\title{
Each One of us was Several: Networks, Rhizomes and Web Organisms
}

\author{
Luke Tredinnick \\ London Metropolitan University, Faculty of Social Science and Humanities, \\ 66-220 Holloway Road, London N7 8DB, UK, <l.tredinnick@londonmet.ac.uk>
}

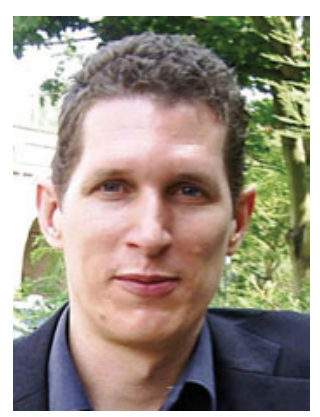

Luke Tredinnick is a Senior Lecturer in Information Management at London Metropolitan University, and course leader for the BSc Media and Communications. He has written a number of books including Digital Information Culture (2008).

Tredinnick, Luke. Each One of us was Several: Networks, Rhizomes and Web Organisms. Knowledge Organization. 40(6), 414-421. 31 references.

Abstract: This paper develops a conceptual analysis of hypertext and the World Wide Web by exploring the contrasting metaphors of the network and the rhizome. The idea of the network has influenced the conceptual thinking about both the web, and its wider socio-cultural influence. The paper develops an alternative description of the structure of hypertext and the web in terms of interrupted and dissipated energy flows. It concludes that the web should be considered not as a particular set of protocols and technological standards, nor as an interlinked set of technologically mediated services, but as a dynamic reorganisation of the socio-cultural system itself that at its inception has become associated with particular forms of technology, but which has no determinate boundaries, and which should properly be constituted in the spaces between technologies, and the spaces between persons.

Received and accepted 1 September 2013

\subsection{Introduction}

This paper tells the story of the network, the rhizome, and the web. Its title is taken from the opening lines of Deleuze and Guattari's A Thousand Plateaus (1987), in which the idea of the rhizome is developed. In that work, the plurality of the self describes the difficulty attributing authorial responsibility within a collaborative text. Here it is used to imply the fragmented and distributed nature of the World Wide Web. Each of us is several because the rhizome of the web dissipates subjectivities, influence, and ideas.

This process can be illustrated by three brief stories of lives transformed by the web. In 2002 a Canadian student filmed himself energetically swinging a golf-ball retriever, and discarded the tape in the basement of the school where it lay forgotten. Eventually finding its way onto the web, within a few years the video had been viewed nine hundred million times. It has since been set to music, augmented with CGI, subjected to parody, televised worldwide, and become the subject of extended legal action. Overnight the Star Wars Kid became a reluctant global sensation (Kahney 2003). Two years later, a nineteen-year old man in New Jersey filmed himself lip-synching to an obscure Moldovan pop song, and uploaded the video to the Newshounds site. View counts rose slowly at first, but within five years had reached seven hundred million. Known as the 'Numa Numa Dance,' the video has since inspired a subgenre of viral lip-synched amateur pop videos (Wei 2010). More recently Howard Davies filmed the plaintive cry of his toddler son when his finger was bitten by the baby Charlie. Wanting to share a video with their godfather, he uploaded it onto YouTube. 'Charlie Bit Me' has now been viewed half a billion times, making minor celebrities of the family (Chittenden 2009). Charlie and Harry had become the latest in a long line of accidental internet stars.

Each of these otherwise unrelated stories exemplifies a peculiarly modern phenomenon. Technology enables both the capture of mundane moments in otherwise unremarkable lives, and their pathogen-like global diffusion. This dissipation transforms those moments into multiplicities, stripping from them the personal contexts in which they were created, and spewing them across culture. Our digital ghosts are several, and persistent; the lives of the acciden- 
tal actors in the stories above were each transformed by their accidental celebrity. The particular ways that this occurred remains dependent on global socio-economic interactions. The same forces by which we are all cradled each day occasionally conspire to generate extraordinary and unpredictable effects. Sometimes a thing as tiny as a URL can change everything.

This kind of electronic ephemera represents a form of social record making with no direct historical parallels (Tredinnick 2010 and 2013). Such records are often trivial in nature; triviality and playfulness distinguishes their mode of cultural production from the prior social record making habits of letters and diaries. But in their sometimes sadistic playfulness, they have another function: testifying transformation of cultural production and dissemination inaugurated by the web. Henry Jenkins has argued that new media technologies inaugurate a participatory culture, enabling individuals to participate in the "appropriation, transformation and recirculation of media content" $(2003,286)$. The grand tributaries of the broadcast-media are giving way to a delta of universal participation. The gates have been thrown open, the gatekeepers disbanded, and the spires of high culture toppled in a great cultural levelling.

Yet this paper makes another argument. Viral video, hoax emails, and related phenomena like the emerging dominance of global internet brands are inevitable outcomes of the structure of the web, reflecting a dynamic asymmetry in the flow of information online. Far from a smooth undulating ocean, the web creates violent sinkhole effects. Drawing our attention to the delta, and preventing us seeing the deeper channels carved through culture, are the ways we habitually frame the web and its influence. In its geometrical purity, the ubiquitous idea of the network calms disequilibrium and imbues the whole system with a spurious unity and tranquillity.

Although superficially similar, the network and the rhizome provide contrasting metaphors for understanding the web. ${ }^{1}$ The rhizome emphasises the asymmetrical nature of interrupted and dissipated information flows, and forefronts "impasses, blockages, incipient taproots, or points of structuration" (Deleuze and Guattari 1987, 15). It provides a description of the web as a dynamic reorganisation of the socio-cultural system that has become associated with particular forms of technology, but that has no determinate boundaries, and which should properly be constituted in the spaces between technologies and persons. The rhizome of the web infiltrates the entire socio-cultural system, and makes several of us all. This paper explores that transformation. To do so it returns to the beginning, when a radical break with the habits of information organisation was first intimated.

\subsection{The birth of the network}

The story of the network and the rhizome begins long before the birth of the internet itself, in the struggle to coordinate scientific and engineering research during the Second World War. Established by executive order of President Roosevelt in 1941, the U.S. Office for Scientific Research and Development had a remit to "develop broad and coordinated plans for the conduct of scientific research in the defense program" (Roosevelt 1941). The OSRD would later play a key role in establishing the Manhattan project. But through the war a more practical problem was preoccupying the extraordinary mind of its first director. Vannevar Bush believed much scientific knowledge remained underutilised, locked in silos of scientific and technical specialism that kept it unknown to those who most needed it. More could be achieved by using technology to break down these disciplinary silos. Those ideas emerged in 1945 in an article entitled "As We May Think." In it Bush outlined what is widely regarded as the first description of a hypertext-like information retrieval system.

The Memex machine was designed to partially automate information storage and retrieval. By exploiting conceptual association between microphotographic records, it weaved old information into new meanings, making knowledge more visible and improving its discoverability. With this design, Bush (1945) sought to overcome "the artificiality of systems of indexing" that dominated information storage and retrieval. Ideas, he suggested, do not respect disciplinary boundaries which impose a false analytical structure on knowledge. He noted (106): "The human mind does not work that way. It operates by association ... in accordance with some intricate web of trails carried by the cells of the brain. It has other characteristics ... memory is transitory."

If the mind worked by association, then so should the Memex, linking records in ways that mirrored human cognition. This image proved persistent in the discourse of the web, but perhaps betrays a naïve understanding of cognitive processes (Ellis 1992). Nevertheless the Memex became principally a machine not for organising information, but for directing attention within a disordered information space. The dichotomy between classification and association was mapped-out in the vocabulary of the paper itself: the "spider web" (Bush 1945, 101) of wires within telephone exchanges suggesting the "mesh of associative trails" (108) and "intricate web of trails" (106) of the Memex. This language itself perhaps proved most influential, and although it was never built, the radical ontology of the Memex lived on in subsequent systems.

The first of these was hypertext, conceived by Ted Nelson as nonlinear writing and explicitly indebted to the Memex (Naughton 1999). Like Bush, Nelson criticised the 
analytical organisation of recorded knowledge, arguing that users should be able to follow information across the boundaries of individual documents. In his design data trails were transformed into transclusions. This structure echoed ideas about the interdependence of written works emerging in post-structuralism (Landow 1997; Tredinnick 2007). Barthes, for example, described the literary text as "a tissue of quotations drawn from the innumerable centres of culture" (1977, 146), which are "anonymous, untraceable" and "quotations without inverted commas" (160). Described as writing's "participation in the discursive space of culture" (Culler 1981, 114), intertexuality situated texts as entangled by affiliation, influence, and association. This idea is clearly suggested by the non-linear and recursive structure of hypertext, which in one sense only sought to forefront the intrinsic intertextuality of all writing.

However, if hypertext channelled wider philosophical notions of writing's recursiveness, in its most significant iteration it was to draw inspiration from another branch of the sciences. Berners-Lee also believed that hierarchical structures inhibited information retrieval, and also sought to harness semantic and associative relationships that would "mimic human association of ideas" (Berners-Lee et al. 1992, 52). Yet this familiar idea was framed by the unfamiliar science of complexity (Tredinnick 2009). In the original proposal Berners-Lee described the "loss of information about complex evolving systems" and described CERN as "a multiply connected 'web' whose interconnections evolve with time" (1989). The qualities of the complex organisation came to define both the problem of information, and its solution. But if Berners-Lee was looking inward at CERN for inspiration, he was also looking outward. The complexity of CERN was situated as "a model in miniature of the rest of world" (BernersLee 1989). He later described society as a fractal with organization at every scale (Berners-Lee 1995). These ideas were eventually expressed in quasi-philosophical terms; in the 1999 he mused (14): "In an extreme view, the world can be seen as only connections, nothing else ... I liked the idea that a piece of information is really defined only by what it's related to and how it is related. There is really little else to meaning. The structure is everything."

This statement weaves the web into a general philosophical ontology. Yet if the web was born in a giddy contemplation of complexity and fractal geometry, its ontological organisation was always more rudimentary. Far from only connections, the web was only independent files. It may stretch "seamlessly from small personal notes on the local workstation to large databases on other continents" (Berners-Lee et al. 1992, 53) but it stretched in only two dimensions, a flat "diagram of circles and arrows" (Berners-Lee 1989). The transclusions of hypertext were rendered as static links; its dynamic intertextuality reduced to a two-dimensional network. The structure of hyperlinks rather than the association of ideas became everything.

Throughout its history, the discourse of the web reveals an ongoing struggle to describe the system of associations around which hypertext is built. This struggle results in series of analogies: the telephone exchange, for example; intertextuality and complex system, each which of both hints at an underlying truth without fully embodying it, and mirrors an underlying tension between the recursive and evolving nature of hypertext, and its description. Bolter notes that "we tend to think of hypertext spatially" (1991, 29); but in an important sense, spatial models fail to fully capture the potentially infinite web. Nevertheless the spatial network became the dominant metaphor, and was coopted into explanations of its social consequences. In ideas such as the network society (Castells 2000-2004), network identities (Fenwick 2007), and network organisations (Snow et al. 2000), the physical network of the internet became conflated with the associative network of the web. This influence of the network metaphor came at the expense of alternative ideas, including a more organic conception of the ontology of information.

\subsection{The network and the rhizome}

At first glance the rhizome and the network appear almost indistinguishable. Both emphasise decentralisation, distribution, and interconnectedness; but the rhizome takes these ideas in a different direction. Drawn from nature, Deleuze and Guattari $(1987,5)$ contrast the tangled rhizome with the well-ordered tree. The system of the tree, each part of which is subdivided into ever finer elements, alludes to both the traditional tree of knowledge, and to the analytical tradition itself, with its reliance on reductionism, and classification. The tree, they suggest, is the image of the world and its root system the image of the canopy, the association established through a mirroring function, implying a mimetic relationship between the foundations of knowledge and the manifest nature of things in the western intellectual tradition. This relationship is underlined by the idea of the root-book as a tidy, organised mimesis of nature.

By comparison, the rhizome is a mass of roots, with no apparent organisation or structure, no centre, nor central organising principle, growing horizontally across the available land. The rhizome is subversive, colonizing and opportunistic, forging ad hoc connections and internal structure. A significant part of its value derives from this organic nature. The rhizome is presented as an invasive species, insensitive to the tidy ideals of ornamental horticulture, spreading relentlessly across culture, resisting both classification and final description. It is a metaphor of wild, untamed nature, and resists the kinds of idealisations 
implied by both geometric figures and analytic reductionism. Analytic systems emerge as an abstract description at only one level of the rhizome, and are otherwise embedded within it.

While the rhizome describes a superficially similar structure to the network, it resists the idea that the web is the sum of its pages and hyperlinks, and that its boundaries can ever be fully delineated. The web tends to be overlaid on the internet as if the two were analogous, but the connections of each system are of a fundamentally different nature. The internet is a physical network, but the web only a series of conceptual relationships; it "is made only of lines" (Deleuze and Guattari 1987, 23); it is "only connections, nothing else” (Berners-Lee 1999, 14). These connections are not technological, nor found in content mark-up, but exist only in the socially situated and mindful habits of uses in their engagement with the entire system. The web independent of this social context of use is merely a collection of files, the associations between them unrealised. Therefore while describing a similar ontology, the rhizome offers an offset view, enabling us to recognise aspects of the web that we might otherwise overlook.

The network implies abstract uniform geometry; the rhizome disorganisation and random assemblages, with isolated instances of structure emerging as temporarily localised phenomena at particular scales. The network implies a self-contained web, forging mimetic relationships with society and cognitive processes but always independent of them (like the world-tree and the root-book). The rhizome by contrast implies a web knitted-in to both individual minds and the socio-cultural system, such that the boundaries between them remain indistinct. The rhizomic web colonises the social system; or perhaps the rhizomic social system colonises the web. Without mimesis, the web becomes a movement within a plane of consistency; the network merely a description of the rhizome at a particular scale; a tracing of its impasses, blockages, and points of structuration. The network implies stasis, but the rhizome emphasises organic evolution without final form, and unyielding to final description. While the network implies each node is integrated into the whole, the rhizome emphasises asignifying rupture and discontinuity.

Most importantly, the network metaphor underplays those aspects of the Memex, hypertext, and the web that are most dynamic, and emphasises those that are most mundane. For Bush, Nelson, and Berners-Lee, the network is already straining to dissolve the distinction between the information and the social and cognitive context in which it is used. Their works attempt to expose the associative fabric of information, to exploit the evolution of ideas and associations, and in Berners-Lee's case to enable self-organising complexity. But half-articulated, and lacking a full theoretical grounding, these ideas merely glimpse out from behind the tangle of telephone exchanges, the technical diagrams of computer networking, and the sublime idealism of fractal geometry. In the rhizome they re-emerge as a fully embodied organic entity.

The contrast between rhizomes and networks exposes the latter as a simplified and idealised description of a more complex whole, a simplification that functions to conceal disorganisation by over-generalising from examples of order. But the rhizome can also be used to construct a description of the ontological organisation of the web that incorporates those allusions to complexity and evolution that the network metaphor has tended to exclude, and also explain more accurately the relationship between the web, cognition, and society. Some sense of this can be attained if we begin to map-out an ontological description of the World Wide Web as a rhizome, and contrast it with that which is suggested by the metaphor of the web.

\subsection{The rhizomic web}

In A Thousand Years of Nonlinear History (1997), Manuel De Landa maps a millennium of historical change by treating human society as a complex self-organising system. He argues that history arises not from great historical figures, nor as a sweeping narrative of progress. The events marked-out in history are largely incidental: consequences rather than causes of historical change. History, De Landa argues, is driven by the transformation of matter-energy. It is a story of the gradual accretion of matter-energy states over time. In a series of apparent phase transitions, the remnants of the past accumulate like geological strata.

This argument is interesting for the idea of the rhizomic web because De Landa traces the philosophy of Deleuze through the lens of complexity theory. The six principles of the rhizome outlined by Deluze and Guattari draw heavily on systems theory, and echo the characteristics of complex systems (see Cilliers 1998; Manson 2000). Indeed, Deleuze and Guattari $(1987,19)$ provide their own gloss on this, describing rhizomes as:

finite networks of automata in which communication runs from any neighbor to any other, the stems or channels do not pre-exist, and all individuals are interchangeable, defined only by their state at a given moment - such that the local operations are coordinated and the final global result synchronized without a central agency.

De Landa makes the association explicit, and shows Deleuze to be a more analytical theorist than often assumed; elsewhere he writes that "Deleuze's work is, from the beginning, concerned as much with physics and mathematics, as it is with art" (De Landa 2000, 40). 
The historically-situated social system is of course rhizomic. The model of matter-energy transformation therefore suggests ways of applying the idea of the rhizome through the lens complexity theory to the web. What follows is a description of the web built not from documents and hyperlinks, but from assemblages of matter-energy evolving in a complex process of reorganisation and exchange through continuous discrete and stable states that accumulate over time. This description is necessarily diffuse, boundless, and ambiguous because the system it describes is also these things. But it transforms the rhizome from an organic metaphor into a model that can be put to work, both to describe the allusions to complexity, evolution, and the cognitive and social context that were lost in the discourse of the web, and even to explain them.

In this model the web is not merely a network of documents and links. Combining the ideas that "the world can be seen as only connections" (Berners-Lee 1999, 14) and "the rhizome is made only of lines" (Deleuze and Guattari 1987, 23), the web becomes a system of relationships that channel energy flows ${ }^{2}$ within various stable states of the matter-energy assemblage; neither the forms of the nodes (documents or minds) nor the description of the assemblage (web or society) matters. This suggests ways of mapping the reorganisation of the matter-energy assemblage, and the factors that influence it. The networkweb of documents and hyperlink emerging as a common description is not itself the rhizome, but merely the crystalline structure deposited by it. The rhizome reflects the integration of the web into the whole social system and the self, as originally implied by Berners-Lee (1999). The rhizome of the web is the ways in which the technical infrastructure of the web is articulated with users to create various temporarily stable assemblages that, at their boundaries, blur into other such assemblages.

Hyperlinks do not physically link pages; they direct attention within a disorganised information space. This space is both contained by the network-web and stretches beyond the network-web into both individual cognition and its aggregation within collective knowledge. Above the document structure of the individual web pages from which the network-web is comprised, the rhizomic web therefore has no structure, no ontology independent of its use. Hyperlinks no longer recall the spider-webbed wires of telephone exchanges, but become only ways of coordinating cognitive processes within an abstract space of relations that is by its nature socially situated. The structure that exists is provided by the integration of the web into human cognitive and social process, when latent associations between elements are activated in individual minds, associations including but not limited to HTML hyperlinks.

The abstract ontological space defined by the associations between individual documents is therefore defined by the flow of energy, and the reorganisation of matterenergy, not within the network-web itself (because hyperlinks themselves transmits nothing) but within the societycognition-web-network assemblage where minds can be put to work to render transformations. In other words, to forge a latent association is not to connect two documents, but to channel the work of active minds. Energy flow here broadly synonymous with the flow of cognitive attention, and the matter-energy assemblage synonymous with the mind-society-web assemblage (although at a larger scale matter-energy simply means matter and energy as normally understood). This gives us a way of exploring the rupture, and dissipation of energy flows across the whole rhizome, rather than just across the network-web, and to explain why the implied geometric regularity of the network misleads us about the violent turbulence with which the web is replete. The web pulsates with different configurations, organisation, and association minute-byminute as its structure is constantly rebuilt by the actions of users.

In this context, Nelson's objections to the organisation of the web take on a new light. He has recently attacked the web for its "ever-breaking links, links going outward only, quotes you can't follow to their origins" (Nelson 2013b). Although perhaps largely an unintentional effect of pragmatic decisions (Berners-Lee 1999), the asymmetry in the implementation of hyperlinks gives them informational value in their own right, and creates ruptures in what superficially appears to be the even geometric space of the network-web. Creating an associative link between documents implies an asymmetry in their relationship. That is to say that a link from one website to another immediately implies a value hierarchy in which the cited site accrues energy at the expense of the citing site. Thus while information remains distributed, energy tends to flow in one direction. One of the first companies to harness the informational of hyperlinks was Google with its PageRank algorithm, which analyses the links between documents to attribute them value. But all the successful social media players, and indeed the very notion of social media itself, depend on exploiting this asymmetry in the structure of hyperlinks to pull users into their grasps.

But it is a mistake to privilege embedded HTML hyperlinks over other forms of association. The network-web may be built from documents and hyperlinks, but the rhizomic web is not. The metaphor of the rhizome emphasises the indistinct boundaries between the network-web, and its broader socio-cultural and technological context. Therefore anything that directs attention within the disorganised information space of the rhizome is of a similar value to the hyperlink, allowing energy to flow from one place to another, and reorganising the matter-energy assemblage minute-by-minute. These other associative con- 
nections may be formal and persistent, such as URLs printed in newspapers, or may be casual and ephemeral such as the mention of a site within a social conversation. They may be technologically enabled such as an embedded link within an email. Or they may be stripped of technological functionality such as the name of a website on a shop sign, or the reiteration of a corporate logo when that logo also forms part of a URL. These kinds of associative connections are critical to the way in which the network-web is knitted-in to culture. They far outnumber embedded HTML hyperlinks, and are generally even less persistent, even evaporating in the air with the conversations in which they embedded.

Deleuze and Guattari suggest, "a rhizome ceaselessly establishes connections between semiotic chains" (1987, 8). The URL once it is recognised functions as an associative link outside of the context of the network-web; we cannot help read them for their associative value. All that matters is that the associative link makes a connection between a part of the rhizome, and a part of the networkweb, that this association enables the potential flow of energy, and that this flow of potentially results in energymatter reorganisation. These semiotic chains therefore extend far beyond the formal boundaries of the networkweb, colonizing the socio-cultural system, forging opportunistic connections and creating ad hoc internal structure within the network-web itself.

Just as with hyperlinks, these other forms of associative connections are generally asymmetrical. Because of this, energy always flows in one direction tending to accumulate at numerous points within the rhizome. This is the crucial departure from Nelson's hypertext, where transclusion ensures associations are neutral in effect. Some points within the rhizome will act as sinkholes, sucking in energy, and becoming more powerful over time. This is because associations with a particular point will tend in the shortterm to encourage more links pointing to that site, and the more such associations the greater the effect, leading gradually to the drawing more and more energy to particularly richly interlinked parts of the whole. Because the total energy is stable, the effect is to draw energy away from everywhere else. Thus over time, the rhizome will generate spontaneous structure, impossible to predetermine or predict, but always acting to mediate the experience of the whole. These may be of lesser or greater significance, may be short lived or remain stable for a very long period. But they will always be subject to the disequilibrium of the rhizome. They will always tend to dissipate eventually because of the antimemory of the web.

\subsection{Since each one of us is several: antimemory and celebrity}

The rhizome makes it clear that the World Wide Web, while it is also a set of protocols, standards, and technologically enabled services, is much more than that. A part of the social system, it is also a dynamic reorganisation of the sociocultural system, a way of forging new relationships, new connections, and new association over time not between documents but between people. This dynamic reorganisation of culture has become associated with particular material forms of technology, but has no determinate boundaries, and should properly be constituted in the spaces between technologies and people, as only connections and nothing else. The web is in this sense merely the crystalline manifestation of a process as old as human culture. Yet the historical influence of web arises from the intensification of matter-energy transformation arising out of rich interconnectedness. The hyper-dimensional meshwork of conceptual associations built on the static network of the internet itself generates infinite new opportunities for energy exchange, and makes multiplicities of everything.

Each one of us is several. In their discussion of the concept, Deleuze and Guattari suggest that "the rhizome is an antigenealogy. It is a short-term memory, or an antimemory" $(1987,23)$ and note that "short term memory includes forgetting as a process" (17). The dynamic nature of the rhizome necessitates the overturning of established, sedimented cultural structures in a process of constant renewal. It is perhaps counter-intuitive to think of the network-web in these terms. In many ways, the web provides a cultural platform which memorialises the most ephemeral of cultural artefacts (Tredinnick 2008). The 'Star Wars Kid' and 'Numa Numa' stories testify that the web sometimes declines to forget. Yet forgetfulness was a part of hypertext from the beginning. In his description of the Memex Machine, Bush noted that "trails that are not frequently followed are prone to fade, items are not fully permanent, memory is transitory" $(1945,106)$. Forgetting was a mechanism that maintained relevance in information discovery, and overcame the sedimentation of ideas within disciplinary silos, where once deposited an idea would remain forever on the model of the great national library.

Surprisingly, perhaps, the transitory nature of cultural memory on the web is fundamental to the unexpected and unpredictable longevity of certain cultural artefacts and records. Antimemory explains how the rhizomic ruptures in the geometric model of the network inevitably creates phenomena such as internet celebrity, viral videos, and memes. Short-term memory relies on repetition, reiteration, and rehearsal. The memory of the web relies neither on the persistence of the record nor its stable location within the information space, but exploits reiteration and 
repetition. Rather like a version of the oral tradition speeded up by many factors, records and cultural artefacts generally survive in the rhizome of the web because they are constantly repeated and varied. Each of these reiterations is merely an echo of the original. The web transforms the individual record, video, journal, diary, report, song, or artwork into multiplicities, both knitted into the fabric of recommendation and citation that underpins the ontological organisation of the web, and also reiterated endlessly in innumerable contexts. The ghosts of the past haunt digital culture condemned to act-out their final moments, never changed only recombined, until they eventually fade away.

We can translate these effects into more ordinary language, because we know already their names. They are called the 'Star Wars Kid,' 'Numa Numa', and 'Charlie Bit Me.' They are called Facebook, Angry Birds, and any number of websites, services, and viral trends which at different scales have emerged during the history of the web, and the vast majority of which have quickly vanished again. These sites and temporary assemblages within the rhizome are always multiplicities, constructed out of the activities of innumerable users. Within them each of us is several in the dissipation of subjectivities, influence and idea.

But the effects of antimemory are also exacerbated by the asymmetricality of the web exacerbates. While energy will tend to accumulate, the antimemory of the web guarantees that those point remain temporary examples of structuration within the rhizome that when considered globally, will tend to dissipate. This is why web phenomena such as those discussed at the beginning of this paper are inevitable, but also why they are unstable; they are the surface ripples of the rhizomic web. It is not for example that a better version of the 'Star Wars Kid' will emerge to replace the original, but only that something different from the original will take its place. It is not that a better search provider will replace Google, or a new social network better Facebook, but that eventually something other than search, and social networking, will arrive.

\section{Notes}

1. The concept of metaphor exploited in this paper draws on Davison's (1984) discussion, in which metaphor is described as "the dreamwork of language" (31) that "serves to alert us to aspects of the world by inviting us to make comparisons" (40); the paper is therefore discursive rather than analytical in its treatment.

2. In complexity theory this process would generally be described in terms of information exchange, but because information on the web also describes semantic content, De Landa's notion of matter-energy is retained here.

\section{References}

Barthes, Roland. 1977. Image music text. London: Fontana Press.

Berners-Lee, Tim. 1989. Information management: a proposal. Available http://www.w3.org/History/1989/proposal. html.

Berners-Lee, Tim. 1995. Hypertext and our collective destiny. Available http://www.w3.org/Talks/9510_Bush/Talk. html

Berners-Lee, Tim. 1999. Weaving the web: the past, present and future of the world wide web by its creator. London: Orion Business Press.

Berners-Lee, Tim, Cailliau, Robert, Groff, Jean-François and Pollermann, Bernd. 1992. World Wide Web: the information universe. Electronic networking 1: 52-8.

Bolter, Jay David. 1991. Writing space: the computer, bypertext and the history of writing. Hove and London: Lawrence Erlbaum Associates.

Bush, Vannevar. 1945. As we may think. Atlantic monthly 176: 101-8.

Castells, Manuel. 2000 - 2004. The information age: economy, society and culture volumes I - III; second edition. Oxford, MA: Blackwell Publishing.

Chittenden, Maurice. 2009. Harry and Charlie DaviesCarr: web gets taste for biting baby. The Sunday times November 1. Available http://www.thesundaytimes.co. $\mathrm{uk} /$ sto/ingear/tech_and_net/article189173.ece

Cilliers, Paul. 1998. Complexity and postmodernism: understanding complex systems. London and New York: Routledge.

Culler, Jonathan. 1981. The pursuit of signs: semiotics, literature, deconstruction. London and New York: Routledge.

Davidson, Donald. 1984. Inquiries into truth and interpretation. Oxford, UK: Oxford University Press.

De Landa, Manuel. 1997. A thousand years of nonlinear history. New York: Zone Books.

De Landa, Manuel. 2000. Deleuze, diagrams, and the genesis of form. Amerikastudien / American Studies 45: 33-41.

Deleuze, Gilles and Guattari, Félix. 1987. A thousand plateaus. Minneapolis, MN: University of Minnesota Press.

Ellis, David. 1992. The physical and cognitive paradigms in information retrieval research. Journal of documentation 48: 45-64.

Fenwick, Tara. 2007. Knowledge workers in the inbetween: network identities. Journal of organizational change management 20: 509-524.

Jenkins, Henry. 2003. Quentin Tarantino's Star Wars? Digital cinema, media convergence, and participatory culture. In Thorburn, David and Jenkins, Henry, eds., Rethinking media change: the aesthetics of transition. Cambridge, MA: MIT Press, pp. 281-312. 
Kahney, Leander. 2003. 'Star Wars kid' gets bucks from blogs. Wired 05.19.03. Available http://www.wired. com/culture/lifestyle/news/2003/05/58881?current Page $=$ all

Landow, George P. 1997. Hypertext 2.0: the convergence of contemporary critical theory and technology. Baltimore, ML and London: John Hopkins University Press.

Manson, Steven. 2000. Simplifying complexity: a review of complexity theory. Geoform 32: 405-14.

Naughton, John. 1999. A brief history of the future: the origins of the internet. London: Weidenfield \& Nicolson.

Nelson, Ted. 2013b. Two cheers for the world wide web. Available http://xanadu.com.au/ted/TN/WRITINGS/ TCOMPARADIGM/tedCompOneLiners.html.

Roosevelt, Franklin D. 1941. Executive order 8807 establishing the Office of Scientific Research and Development. Available http://www.presidency.ucsb.edu/ws/?pid=16137.

Snow, Charles C., Miles, Raymond E. and Coleman, Henry J., Jr. 2000. Managing 21st century network organizations. In McLoughlin, Ian, Preece, David, and Dawson, Patrick ,eds., Technology, organizations and innovation: towards 'real virtuality'? London: Routledge, pp. 1621-38.
Tredinnick, Luke. 2007. Post-structuralism, hypertext, and the world wide web. Aslib proceedings 59: 169-86.

Tredinnick, Luke. 2008. Digital information culture: the individual and society in the digital age. Oxford, UK: Chandos Publishing.

Tredinnick, Luke. 2009. Complexity and the web. Journal of documentation 65: 797-816.

Tredinnick, Luke. 2010. Rewriting history: digital discourse and the nature of the past. In Weller, Toni, ed., Information history in the modern world. London: P. MacMillan, pp. 175-98.

Tredinnick, Luke. 2013. The making of history: remediating historicised experience. In Weller, Toni, ed., History in the digital age. London and New York: Routledge, pp. 39-60.

Wei, William. 2010. Where are they now? Numa Numa guy is creating the next CollegeHumor. Business insider Jun. 18. Available http://www.businessinsider.com/ where-are-they-now-numa-numa-guy-is-creating-thenext-college-humor-2010-6. 